\title{
Rehabilitation of Oncological Amputee Patients
}

\author{
Metka Prešern-Štrukelj, Urška Zupanc and Metka Zalar \\ Department for Rehabilitation of Amputee Patients, University Rehabilitation Institute "Soča”, Ljubljana 1000, Slovenia
}

Received: January 10, 2015 / Accepted: February 17, 2015 / Published: February 28, 2015.

\begin{abstract}
Peripheral vascular disease is the main reason for lower limb amputation, mostly present in old persons. The number of lower limb amputations due to cancer is small, but affects all age groups. Surgery is the primary (main) treatment for most bone tumors, the main goal is to remove all of the tumor. Sometimes limb amputation is the only possible solution, resulting in severe impairment of body function and activity limitations. The final goal of rehabilitation is to enable patients to re-integrate to the highest possible level into their previous social life and work. The article presents the functional outcome of patients with lower limb amputation due to oncological disease - cancer of bone or soft tissue admitted for rehabilitation to the University Rehabilitation Institute Soča in the period from 2002 to 2012. During this period 67 amputees were admitted and 60 of them were fitted with appropriate lower limb prosthesis. Younger age and transtibial level of amputation were of better functional outcome than in transfemoral or hip disarticulation amputees.
\end{abstract}

Key words: Amputation of lower limb, oncological disease, rehabilitation program.

\section{Introduction}

PAD (Peripheral vascular disease) is the main reason for lower limb amputation, and mostly affects older population. The number of persons with lower limb amputation due to cancer is small, but affects all age groups [1].

The American Cancer Society estimated for cancer of the bones and joints for 2014 [2]:

- About 3,020 new cases will be diagnosed.

- About 1,460 deaths from these cancers are expected.

Primary cancers of bones account for less than $0.2 \%$ of all cancers.

In adults, over $40 \%$ of primary bone cancers are chondrosarcomas. This is followed by osteosarcomas (28\%), chordomas (10\%), Ewing cancers $(8 \%)$, and malignant fibrous histiocytoma/fibrosarcomas (4\%). The remainder of cases are several rare types of bone cancers. In children and teenagers (those younger than 20 years), osteosarcoma (56\%) and Ewing cancers

Corresponding author: Metka Prešern-Štrukelj, Ph.D., research field: rehabilitation of amputee patients. E-mail: metka.presern@ir-rs.si.
(34\%) are much more common than chondrosarcoma (6\%) [2].

Surgery is the primary (main) treatment for most bone tumors, the main goal is to remove all of the tumor. If even a few cancer cells are left behind, they can grow and multiply to make a new tumor. Removing some normal-looking tissue helps ensure that all of the tumor is removed.

In some cases limb amputation is the only solution. Afterwards the patient should be included in the amputee rehabilitation program. If possible, the patient should meet the rehabilitation specialist before surgery to explain him the rehabilitation program.

Amputation of lower limb causes severe impairment of body function and activity limitations. Cancer rehabilitation is a varied and challenging field of increasing public health importance. An accruing evidence base suggests that conventional rehabilitative interventions succeed in preserving and restoring the functional status of cancer patients [3].

Early rehabilitation is essential and is carried out already at departments for surgery where it focuses on correct positioning of the stump in bed and on a 
wheelchair as well as on correct application of compression dressing on the stump aimed at the prevention of swelling and stump formation, a prerequisite for successful prosthetic fitting at a later stage [3].

At the University Rehabilitation Institute Soča the amputee patients are included in the complex team rehabilitation program (PRM specialist, physiotherapist, occupational therapist, nurses, social worker, psychologist, prosthetic specialist...). The final goal of rehabilitation is to enable patients to re-integrate themselves as fully as possible into their previous social life and work.

With new treatment options, the number of patients surviving cancer is increasing. These patients lead functional and productive lives despite the legacy of their disease.

\section{Materials and Methods}

With the retrospective study the authors analysed rehabilitation outcome of patients with lower limb amputation due to oncological disease admitted for rehabilitation to the University Rehabilitation Institute in the period from 2002 to 2012.

During this period 67 lower limb amputees due to cancer were admitted to the institute ( 35 men, 32 women).

The patients were of all age groups (Fig. 1), average age 58 years (range 17-85 year).
Some other characteristics of our group of amputee patients are shown in Figs. 2 and 3.

\section{Results}

Out of 67 amputees 60 were fitted with appropriate lower limb prosthesis.

In seven cases the prosthetic alignment failed because of the progression of the disease ( 3 patients) and poor healthy status (4 patients).

Rehabilitation outcome of patients with lower limb amputation was tested with Functional Independence Measurement (motor FIM, max 91) at admission and discharge from the Rehabilitation Institute (Fig. 4), with walking endurance test (6 min walking test), and walking speed test (10 meters walking time) (Table 1).

\section{Discussion}

The main reason for lower limb amputation is peripheral vascular disease (PAD), the next reasons are different accidents (traffic, work) and on the third place there are different cancers of bone and soft tissue [3]. Peripheral vascular disease is mainly present in older persons, trauma patients are mainly young and middle age, cancer patients are of all age groups. The average age of the authors' oncological patients was 58 years (17-85), most of the patients (67.2\%) were over 60 years old, and only 2 patients (3\%) were younger than 20. In some other studies the patients were some years younger [4].

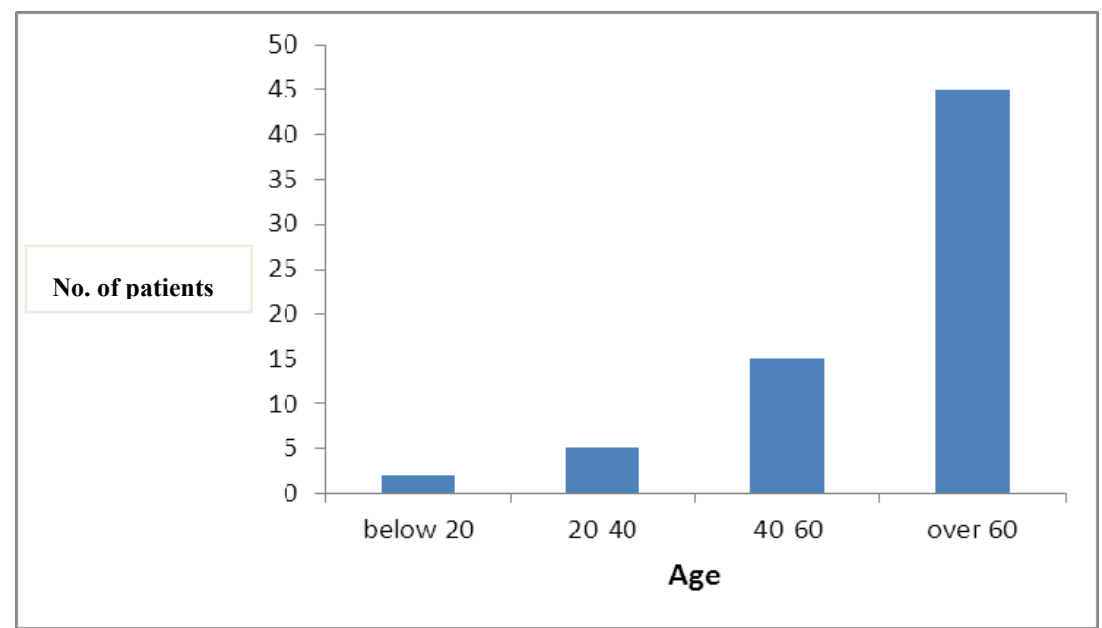

Fig. 1 Different age groups of the amputees. 


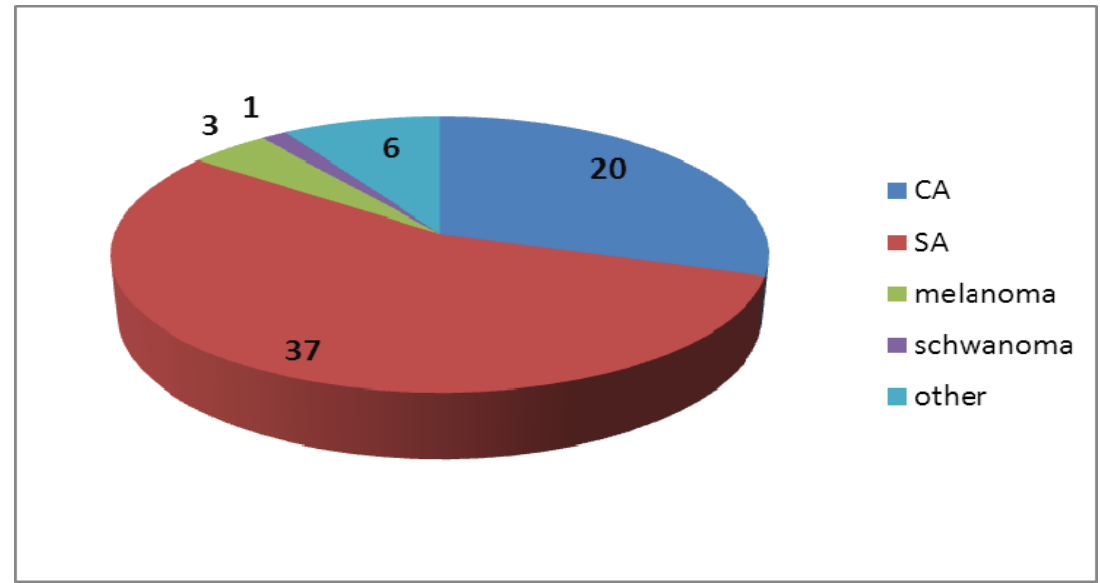

Fig. 2 Histological types of cancers in the amputees.

CA-carcinoma; SA- sarcoma.

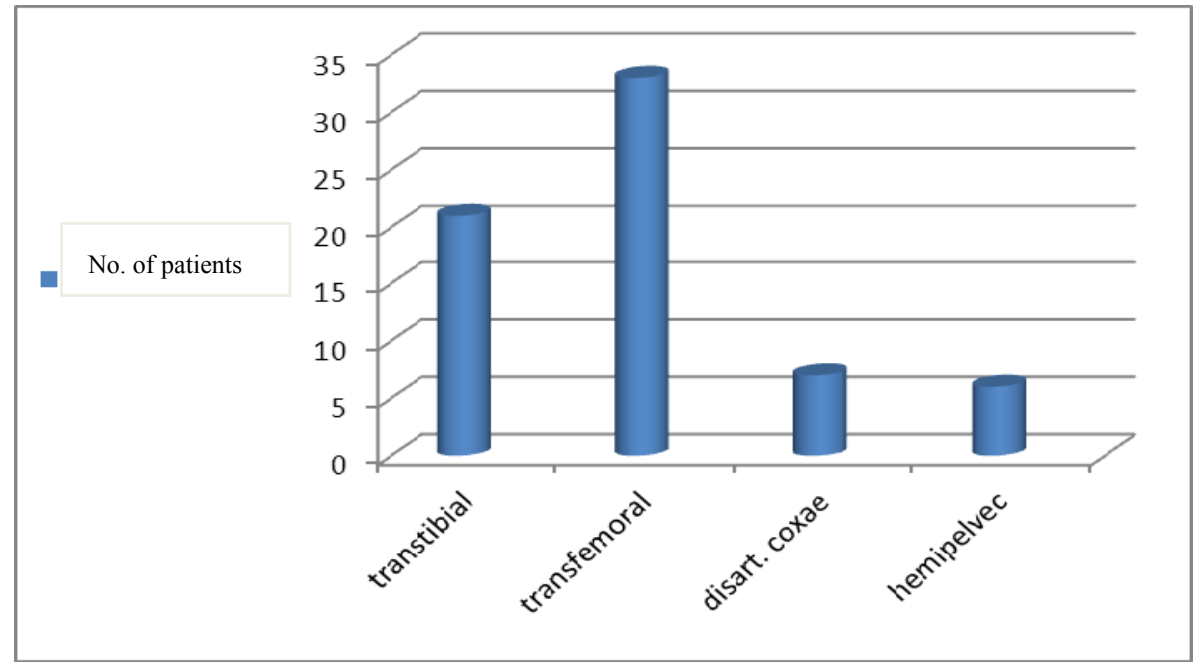

Fig. 3 The level of amputation of lower limb in the group of amputees.

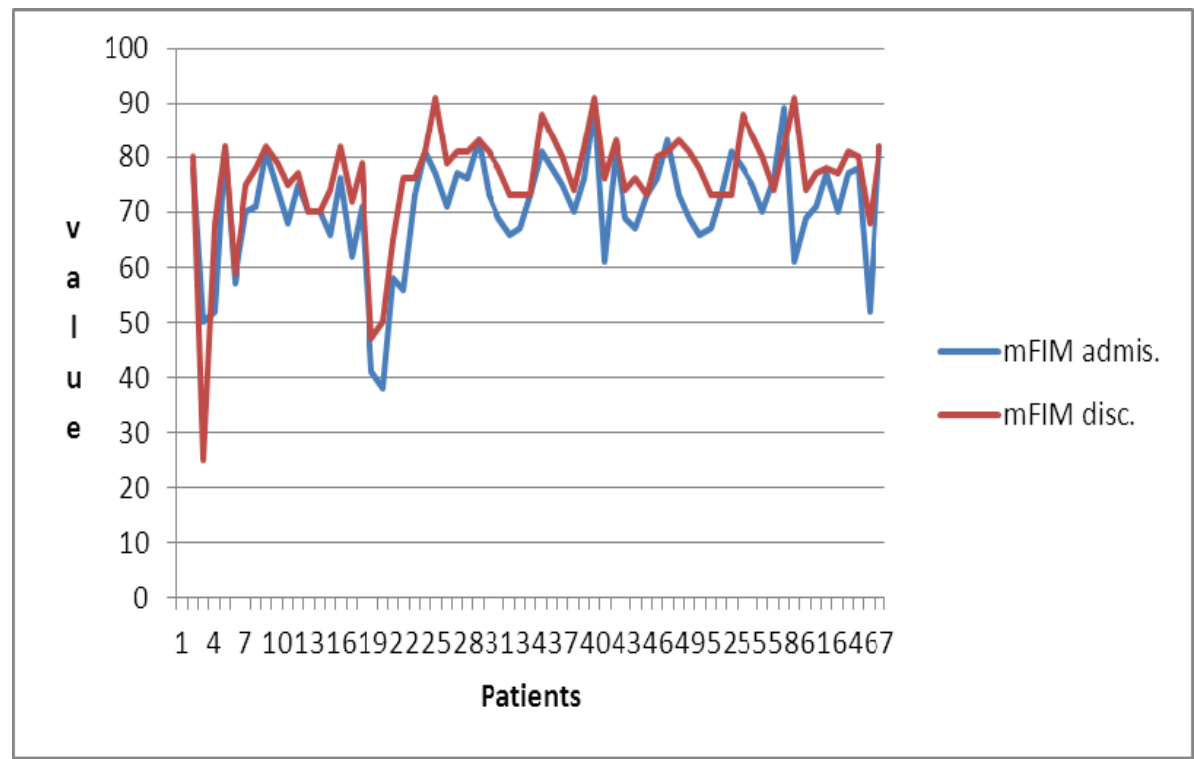

Fig. 4 Motor FIM (mFIM) of the amputees at admission and discharge from the Rehabilitation Institute. 
Table 1 Data of rehabilitation outcome of same amputees.

\begin{tabular}{lllllll}
\hline Age $(\mathrm{y})$ & 46 & 61 & 84 & 51 & 75 & 18 \\
\hline Level of amputation & TF & TF & TT & TT & HD & TF \\
10 meters walking time-walking speed (sec) & 24 & 26 & 35 & 9 & 35 & 13 \\
6 min. walking test-walking endurance (m) & 172 & 130 & 80 & 346 & 80 & 195 \\
mFIM at admission and discharge & $77 / 81$ & $78 / 80$ & $69 / 74$ & $82 / 82$ & $56 / 76$ & $85 / 89$ \\
\hline
\end{tabular}

TF-transfemoral; TT-transtibial; HD-hip disarticulation

About 50\% of lower limb amputees due to leg tumors have a life expectancy more than five years [5]. So in all the amputees the prostheses for a high level of activity are indicated to provide the maximal possibility for efficient psychosocial reintegration [4]. The authors fitted $60(89.5 \%)$ out of total 67 the patients with lower limb prosthesis in seven cases (10.4\%) the prosthetic fitting was not possible because of progression of the disease or very bad healthy status.

At discharge the patients with transtibial amputation of lower limb and in younger age were walking faster and made longer distance than transfemoral or hip disarticulation amputees, but the change in motor FIM was smaller, because already at admission they were in better condition. The change in motor FIM was the biggest (20) in hip disarticulation amputee, because of the high level of amputation and of age ( 75 years).

\section{Conclusions}

Rehabilitation outcome of patients with lower limb amputation depends on the patients' age, their physical condition, the level of amputation of lower limb, their primary disease and comorbidities and, last but not least, on rehabilitation program. The final goal of rehabilitation is to enable patients to re-integrate themselves as fully as possible into their previous social life and work.

\section{References}

[1] Baumgartner, R., and Botta, P. 1995. Amputation und Prosthesenversorgung der unteren Extremitat. Enke Verlag: Stutgart.

[2] American Cancer Society. 2014. Cancer Facts and Figures. Atlanta.

[3] Cheville, A. 2007. "Cancer Rehabilitation." In Physical Medicine and Rehabilitation, edited by Braddom, R. L. Philadelphia: Sounders/Elsevier.

[4] Kauzlarič, N., Kauzlarić, K. S., and Kolundžić, R. 2007. "Prosthetic Rehabilitation of Persons with Lower Limb Amputations due to Tumour." Eur J Cancer Care 16 (3): 238-43.

[5] Ferrapie, A. L., Brunel, P., Besse, W., Altermatt, E., Bontoux, L., and Richard, I. 2003. "Lower Limb Proximal Amputation for a Tumour: A Retrospective Study of 12 Patients." Prosth Orthot Int 27: 179-85. 